\title{
Burnout and work-life balance among physicians: the role of migration background
}

\author{
Felix S. Hussenoeder ${ }^{1 *}$ D, Erik Bodendieck ${ }^{2}$, Ines Conrad ${ }^{1}$, Franziska Jung ${ }^{1}$ and Steffi G. Riedel-Heller ${ }^{1}$
}

\begin{abstract}
Background: We want to analyze the effect of migration background (MB) on physician burnout and work-life balance.

Methods: In September 2019, physicians from various specialties answered a questionnaire on work and health. We analyzed a subsample of 526 physicians that were working full time in a hospital, $14 \%$ with an MB and $47.9 \%$ were female.

Results: Multivariate analysis showed that physicians with an MB exhibit significantly less favorable scores on all three burnout dimensions, and this effect persisted in the regression analysis after adding age, gender, and marital status as control variables. There were no differences with regard to work-life balance.

Conclusions: To our knowledge, our study is the first one to suggest that MB plays a significant role in physician mental health. Future research will benefit from identifying the factors behind that connection, e.g., problems related to acculturation, communication and social integration, which can then be addressed by policymakers in order to maintain and improve the medical infrastructure.
\end{abstract}

Keywords: Burnout, Work-life balance, Physicians, Migration background

\section{Background}

Research shows that physicians, compared to the general population, are more likely to experience burnout and lowered work-life balance (WLB) $[1,2]$. Burnout is characterized by feelings of energy depletion or exhaustion; increased mental distance from one's job, or feelings of negativism or cynicism related to one's job; and a decrease in professional efficacy [3]. It is often associated with unfavorable WLB $[4,5]$. Due to physicians' role in the health system, their mental health has a direct impact on the population, and studies show that physicians' WLB and burnout are connected to medical errors $[6,7]$. In

\footnotetext{
* Correspondence: Felix.Hussenoeder@medizin.uni-leipzig.de

${ }^{1}$ Institute of Social Medicine, Occupational Health and Public Health, University of Leipzig, Ph.-Rosenthal-Str. 55, 04103 Leipzig, Germany Full list of author information is available at the end of the article
}

addition, physician burnout is associated with reduced professional work effort and lower quality of care $[8,9]$. Conservative estimations suggest that physician turnover and reduced clinical hours due to burnout generate costs of approximately 4.6 billion USD each year in the US [10]. As studies suggest, individuals from a cultural background different from the country they are working and living in may be especially vulnerable to mental health problems; however, to our knowledge there is no research on the relationship between migration status and physician burnout and WLB. The literature on burnout and migration is focused on workers, conducted in other cultural settings, and it does not analyze the role of migration vs. nonmigration. Specifically, studies address the relationships between burnout and occupational stress, life satisfaction, identity and other factors in Chinese migrant workers

(c) The Author(s). 2021 Open Access This article is licensed under a Creative Commons Attribution 4.0 International License, which permits use, sharing, adaptation, distribution and reproduction in any medium or format, as long as you give appropriate credit to the original author(s) and the source, provide a link to the Creative Commons licence, and indicate if changes were made. The images or other third party material in this article are included in the article's Creative Commons licence, unless indicated otherwise in a credit line to the material. If material is not included in the article's Creative Commons licence and your intended use is not permitted by statutory regulation or exceeds the permitted use, you will need to obtain permission directly from the copyright holder. To view a copy of this licence, visit http://creativecommons.org/licenses/by/4.0/ The Creative Commons Public Domain Dedication waiver (http://creativecommons.org/publicdomain/zero/1.0/) applies to the data made available in this article, unless otherwise stated in a credit line to the data. 
[11-14], and the associations between burn out and work characteristics and perceived control in care workers in Israel $[15,16]$. In addition, work on migration and WLB is mainly interested in conceptual questions and applies qualitative methodology, i.e., research is focused on the interrelations between different WLB-related domains, the application of a feminist perspective, minority migrant groups, and critical discussion [17-20]. While research does not directly address the relationship between migration and burnout/ WLB in physicians, studies connect mental health problems and stress in expats and foreign born workers [21-23]. Others show that physicians with a migration background (MB) may experience problems related to patient communication [24], social integration and relationships $[25,26]$. In this article, we want to fill a gap in the literature by analyzing the connection between $\mathrm{MB}$ and physician burnout and work-life balance in Germany.

\section{Methods}

\section{Study design and sample}

In September 2019, physicians from different specialties working in the Federal State of Saxony, a region in the Eastern part of Germany, were randomly selected and asked to fill out a questionnaire on work and health that they received via mail. From the original sample of 1412 physicians (MB: 9.0\%), we only included physicians that were working full time in a hospital $(N=570)$. After removing 44 participants due to missing values, the final sample contained 526 persons, $76(14.4 \%)$ with an MB. The fact that our final sample contained a higher percentage of physicians with an MB compared to the original sample is unsurprising since our data shows that physicians with an MB are more likely to work in hospitals and full time. This study was approved by the ethics committee of Leipzig University.

\section{Assessment}

Sociodemographic data including age, gender, and marital status were assessed. In addition, MB was assessed via one item asking "Is German your first language?" (German is the official language of Germany). In case it was not, participants could then state their native language. We chose language status as an indicator for migration background based on the suggestions by Schenk et al. [27]. The advantages of language status as a proxy for $\mathrm{MB}$ are its simplicity and the fact that it can easily be answered. The fact that it includes a variety of different countries of origin is rather an advantage than a problem at this early stage of research.

\section{Burnout}

We used the German version of the Maslach Burnout lnventory - General Survey (MBI-GS [28, 29]) to measure burnout. The MBI-GS has been validated in a variety of countries around the globe [30-32]. It contains the three dimensions (1) exhaustion, (2) cynicism, and (3) professional efficacy. Following the approach by Kalimo et al. [33], we first inverted the professional efficacy scale, and then added weighted average scores of all three scales in order to compute burnout scores (0.4*exhaustion $+0.3^{*}$ cynicism $+0.3 *$ professional efficacy). While burnout scores could theoretically range from 0 (= never $)$ to 6 (= every day), in our sample they were between 0.00 and 5.15 .

\section{Work-life balance}

We assessed global, subjective WLB with the German Trierer Kurzskala (TKS-WLB [34],) consisting of five statements that can be answered on a Likert-scale from 1 (= absolutely not true) to 6 (= absolutely correct). Participants' scores ranged between 1 and 6 .

\section{Statistical analyses}

We used SPSS Version 25 for the statistical analysis. We compared means between physicians with and without $\mathrm{MB}$ using independent $\mathrm{t}$-tests. We then applied multiple linear regressions to analyze the effects of $\mathrm{MB}$ on burnout and WLB controlling for age, gender, and marital status.

\section{Results \\ Descriptive characteristics}

Our sample contained 526 individuals of which $47.9 \%$ were female and $14.4 \%$ had an MB. Participants with $\mathrm{MB}$ named a wide array of first languages: Czech (10), Russian (9), Slovakian (9), Arabic (8), and 17 other languages, each specified by less than five participants. Table 1 shows the general characteristics of the study population.

\section{Burnout and WLB: differences between physicians with and without migration background}

While physicians with MB exhibit higher burnout scores, there is no significant difference with regard to WLB (Table 2).

\section{Migration background as a predictor of burnout and WLB} Table 3 shows the regression analysis with MB as a predictor of burnout and WLB, controlling for age and gender. Physicians from a different cultural background exhibit significantly higher exhaustion, cynicism, and total burnout as well as less professional efficacy, while there is no significant impact of MB on WLB. Age is negatively associated with burnout and positively with WLB, and men exhibit better WLB than women. There are no associations between marital status and outcome. 
Table 1 General characteristics of the study population

\begin{tabular}{llll}
\hline & Total $(\boldsymbol{N}=\mathbf{5 2 6})$ & Without MB $(\boldsymbol{N}=\mathbf{4 5 0})$ & With MB (N=76) \\
\hline Age (Mean) n.s. & $39.9(10.9)$ & $40.2(11.1)$ & $38.5(9.1)$ \\
Gender (female) n.s. & $252(47.9 \%)$ & $223(49.6 \%)$ & $29(38.2 \%)$ \\
Marital Status** & & & $44(57.9 \%)$ \\
$\quad$ Married & $264(50.2 \%)$ & $220(48.9 \%)$ & $15(19.7 \%)$ \\
In a relationship & $182(34.6 \%)$ & $167(37.1 \%)$ & $17(22.4 \%)$ \\
$\quad$ Single & $80(15.2 \%)$ & $63(14.0 \%)$ & \\
\hline
\end{tabular}

Note: ${ }^{*} p \leq 0.05 ;+{ }^{* *} p \leq 0.01 ;{ }^{* * *} p \leq 0.001 ; n . s$. not significant (referring to differences between physicians with and without MB), $M B$ migration background. Continuous variables are given as mean (standard deviation), and $p$-values refer to independent t-tests; categorical variables are displayed as numbers (percentages), and $p$-values refer to $\mathrm{Chi}^{2}$-tests

\section{Discussion}

Multivariate analysis showed significant differences between physicians with and without MB with regard to all dimensions of burnout, but there was no significant difference in WLB. Once we include age and gender as control variables for the regression analysis, having an MB still predicted higher exhaustion, cynicism, and total burnout as well as lower professional efficacy but had no effect on WLB.

Our study shows that, following the classification of burnout scores by Kalimo et al. [33], scores from physicians with (2.3) and without (1.8) MB would be categorized as exhibiting "some burnout symptoms" (1.503.45), reflecting results from the literature that shows the increased risk of physicians for burnout $[1,2]$. Also the alleviating effect of age on burnout can be found in the literature and could be attributed to years of professional experience [35].

MB had a significant effect on burnout. These results are in line with a recent study that showed slightly higher burnout scores in employees with an MB compared to those without an MB in Germany [36]. While we did not explicitly ask physicians about the time they already lived in Germany, due to our process of random sampling from a broad and diverse sample, it is very likely that only few of the participants had recently immigrated. Hence the effect of cultural background cannot be explained by the current event of relocation and

Table 2 Differences in burnout and work-life balance between physicians with and without migration background

Without MB $(N=450) \quad$ With MB $(N=76)$

\begin{tabular}{lll}
\hline Burnout & & \\
Exhaustion** & $2.6(1.4)$ & $3.3(1.6)$ \\
Cynicism** $^{*}$ & $1.6(1.3)$ & $2.1(1.4)$ \\
Professional Efficacy*** $^{* * 1}$ & $5.1(0.8)$ & $4.7(0.8)$ \\
Burnout Score $^{\text {a***}}$ & $1.8(1.0)$ & $2.3(1.1)$ \\
Work-Life Balance & $3.2(1.1)$ & $3.0(1.2)$ \\
\hline
\end{tabular}

Note: ${ }^{*} p \leq 0.05 ;{ }^{* *} p \leq 0.01 ;{ }^{* *} p \leq 0.001$. The significance of mean differences was analyzed using independent t-tests. $M B$ migration background

${ }^{a}$ Computation of the total burnout score according to Kalimo et al. [33] its psychosocial repercussions, e.g., in the form of a "culture shock". However, other stressors related to communication, cultural difficulties, and social integration may be more persistent and have an impact on burnout scores [22, 37]. In addition, physicians from other countries may also be exposed to workplace discrimination [38]. Clearly, there are multiple potential stressors and future research needs to explore which mechanisms are important for which group of physicians, in terms of cultural background, age, gender, etc., at which state of the acculturation process. In addition, some physician behaviors could represent helpful resources as a recent German study showed that urologists with an MB exhibited a lower risk of burnout when they read more nonmedical books [39].

There was no effect of cultural background on WLB, and both groups of physicians exhibited rather low scores when compared to other occupational groups like managers and teachers [34]. The latter result is surprising since research suggests a connection between physician WLB and burnout $[4,40]$. It points in the direction that higher burnout scores in foreign physicians are not a consequence of a worse WLB of that population, but are rather a consequence of other factors, like the ones mentioned in the previous paragraph. Identifying and addressing these underlying factors is of key importance in order to attract and retain foreign physicians and health personnel and thereby maintain and build the health infrastructure for the future.

\section{Limitations}

While this study has several advantages, e.g., being the first of its kind utilizing a German sample, it also has certain limitations. For instance, physicians with MB exhibited a great variety of native languages, from Russian, Polish, and Bulgarian to Greek, and it was not clear how long they were in the country. Hence, future research may benefit from focusing on a more specific group of non-native speakers and take into account the temporal dimension. In addition, our regression analysis explained 
Table 3 Prediction of burnout and work-life balance by migration background ( $N=526$, unstandardized regression coefficients)

\begin{tabular}{|c|c|c|c|c|c|}
\hline & Exhaustion & Cynicism & Professional Efficacy & Burnout Score $^{a}$ & Work-Life Balance \\
\hline$\overline{M B}$ (without $\left.{ }^{b}\right)$ & $0.67^{* * *}$ & $0.54^{* *}$ & $-0.34^{* * *}$ & $0.53^{* * *}$ & -0.22 \\
\hline Age & $-0.02^{* *}$ & $-0.02^{* *}$ & $0.01^{* *}$ & $-0.02^{* * *}$ & $0.01 * *$ \\
\hline Gender (male $\left.{ }^{b}\right)$ & 0.19 & -0.08 & 0.00 & 0.05 & $-0.41^{* * *}$ \\
\hline \multicolumn{6}{|c|}{ Marital status (married ${ }^{b}$ ) } \\
\hline In a relationship & 0.08 & 0.03 & -0.06 & 0.06 & 0.03 \\
\hline Single & 0.13 & 0.02 & -0.12 & 0.09 & -0.08 \\
\hline Constant & 3.18 & 2.29 & 4.73 & 2.34 & 2.88 \\
\hline$R^{2}$ & .06 & .04 & .05 & .07 & .06 \\
\hline
\end{tabular}

Note: ${ }^{*} p \leq 0.05 ;+{ }^{* *} p \leq 0.01 ;{ }^{* *} p \leq 0.001 . \mathrm{MB}=$ migration background

${ }^{a}$ Computation of the total burnout score according to Kalimo et al. [33]

"The category coded as " 0 " (= reference category) is presented in brackets

only little variance, and future research should therefore investigate potential additional factors to include.

\section{Conclusions}

International studies show that physicians are more likely to exhibit higher burnout scores and less WLB than the general population $[1,2]$. We wanted to analyze in how far physicians' MB is connected to these phenomena, and our study suggests that physicians with an $\mathrm{MB}$ are more affected by burnout but there is no significant connection with WLB. Therefore, more research is needed to identify the mechanisms and processes that link MB to burnout in order to create a scientific foundation for measures and interventions to improve the situation of physicians with an $\mathrm{MB}$, and to maintain the medical infrastructure in the long run.

\section{Acknowledgements}

Not applicable.

\section{Authors' contributions}

FSH and IC designed the study, performed the analysis, interpreted the results, and drafted the manuscript. SGRH and IC contributed to the interpretation of results, and to manuscript revision. EB and FJ contributed to data collection, study organization, and the revision of the manuscript. All authors read and approved the final manuscript.

\section{Funding}

This paper was supported by the State Chamber of Physicians of Saxony and the University of Leipzig. Funding did not affect the design of the study, the collection, analysis, and interpretation of data and the writing of the manuscript. We acknowledge support from Leipzig University for Open Access Publishing. Open Access funding enabled and organized by Projekt DEAL.

\section{Availability of data and materials}

The dataset used and analyzed during the current study is available from the corresponding author on reasonable request.

\section{Declarations}

Ethics approval and consent to participate

This study was approved by the ethics committee of the University of Leipzig (reference number: 196/19-ek). Participants have given consent for their data to be used in the research.
Consent for publication

Not applicable.

\section{Competing interests}

The authors declare that they have no competing interests.

\section{Author details}

${ }^{1}$ Institute of Social Medicine, Occupational Health and Public Health, University of Leipzig, Ph.-Rosenthal-Str. 55, 04103 Leipzig, Germany. ${ }^{2}$ General Practice, Dresdener Str. 34 a, 04808 Wurzen, Germany.

Received: 15 February 2021 Accepted: 15 July 2021

Published online: 29 July 2021

\section{References}

1. Shanafelt TD, Boone S, Tan L, Dyrbye LN, Sotile W, Satele D, et al. Burnout and satisfaction with work-life balance among US physicians relative to the general US population. Arch Intern Med. 2012;172(18):1377-85.

2. Shanafelt TD, Hasan O, Dyrbye LN, Sinsky C, Satele D, Sloan J, et al. Changes in Burnout and Satisfaction With Work-Life Balance in Physicians and the General US Working Population Between 2011 and 2014. Mayo Clin Proc. 2015:90(12):1600-13.

3. World Health Organization. International classification of diseases for mortality and morbidity statistics (11th Revision); 2018. Available from: URL: https://icd.who.int/browse11/l-m/en.

4. Rabatin J, Williams E, Baier Manwell L, Schwartz MD, Brown RL, Linzer M Predictors and outcomes of burnout in primary care physicians. J Prim Care Community Health. 2015;7(1):41-3. https://doi.org/10.1177/215013191 5607799.

5. Schwartz SP, Adair KC, Bae J, Rehder KJ, Shanafelt TD, Profit J, et al. Work-life balance behaviours cluster in work settings and relate to burnout and safety culture: a cross-sectional survey analysis. BMJ Qual. 2019;28(2):142.

6. Avgar AC, Givan RK, Liu M. A balancing act: work-life balance and multiple stakeholder outcomes in hospitals. Br J Ind Relat. 2011;49(4):717-41. https:// doi.org/10.1111/j.1467-8543.2010.00839.x.

7. Tawfik DS, Profit J, Morgenthaler TI, Satele DV, Sinsky CA, Dyrbye LN, et al. Physician burnout, well-being, and work unit safety grades in relationship to reported medical errors. Mayo Clin Proc. 2018;93(11):1571-80 Available from: URL: http://www.sciencedirect.com/science/article/pii/S00256196183 03720 .

8. Klein J, Grosse Frie K, Blum K, von dem Knesebeck O. Burnout and perceived quality of care among German clinicians in surgery. Int J Qual Health Care. 2010;22(6):525-30. https://doi.org/10.1093/intqhc/mzq056.

9. Shanafelt TD, Mungo M, Schmitgen J, Storz KA, Reeves D, Hayes SN, et al. Longitudinal study evaluating the association between physician burnout and changes in professional work effort. Mayo Clin Proc. 2016;91(4):422-31 Available from: URL: http://www.sciencedirect.com/science/article/pii/S002 5619616001014.

10. Han S, Shanafelt TD, Sinsky CA, Awad KM, Dyrbye LN, Fiscus LC, et al. Estimating the Attributable Cost of Physician Burnout in the United States. Ann Intern Med. 2019;170(11):784-90. 
11. Li X, Zhang H, Zhang J. The double-edged effects of dual-identity on the emotional exhaustion of migrant workers: an existential approach. Front Psychol. 2020;11:1266. https://doi.org/10.3389/fpsyg.2020.01266.

12. Luo H, Yang H, Xu X, Yun L, Chen R, Chen Y, et al. Relationship between occupational stress and job burnout among rural-to-urban migrant workers in Dongguan, China: a cross-sectional study. BMJ Open. 2016;6(8):e012597. https://doi.org/10.1136/bmjopen-2016-012597.

13. Shen $\mathrm{H}$, Huang C. Domestic migrant workers in China's hotel industry: an exploratory study of their life satisfaction and job burnout. Int J Hosp Manag. 2012;31(4):1283-91 Available from: URL: https://www.sciencedirect. com/science/article/pii/S027843191200045X

14. Zhao X, Tuo A, Peng A, He W, Zhu P, Yan Z. Analysis of occupational burnout and its influencing factors of colliery migrant workers in Guizhou Province. Wei Sheng Yan Jiu. 2015;44(6):887-91.

15. Cohen-Mansfield J, Golander H. Predictors of migrant live-in care workers' burden/burnout and job satisfaction when caring for frail older persons in Israel. J Gerontol B Psychol Sci Soc Sci. 2020;76(6):1151.

16. Shinan-Altman S, Ayalon L. Perceived control among migrant live-in and local live-out home care workers in Israel. Aging Ment Health. 2019;23(2): 189-95. https://doi.org/10.1080/13607863.2017.1401584.

17. Ali F, Malik A, Pereira V, Al AA. A relational understanding of work-life balance of Muslim migrant women in the west: future research agenda. Int J Hum Resour Manag. 2017;28(8):1163-81. https://doi.org/10.1080/095851 92.2016.1166784

18. Dyer S, McDowell L, Batnitzky A. Migrant work, precarious work-life balance: what the experiences of migrant workers in the service sector in greater London tell us about the adult worker model. Gend Place Cult. 2011;18(5): 685-700. https://doi.org/10.1080/0966369X.2011.601808.

19. Dyer SL, Xu Y, Sinha P. Migration: a means to create work-life balance? J Manage Org. 2018;24(2):279-94 Available from: URL: https://hdl.handle.net/1 0289/13137

20. Rouse J, Treanor L, Fleck E, Forson C. Contextualising migrant black business women's work-life balance experiences. Int J Entrep Behav Res. 2013.

21. Cantor-Graae E, Pedersen CB. Full Spectrum of Psychiatric Disorders Related to Foreign Migration: a Danish population-based cohort study. JAMA Psychiatry. 2013;70(4):427-35.

22. Doki S, Sasahara S, Matsuzaki I. Stress of working abroad: a systematic review. IAOEH. 2018;91(7):767-84 Available from: URL: https://doi.org/10.1 007/s00420-018-1333-4.

23. Truman SD, Sharar DA, Pompe JC. The mental health status of expatriate versus U.S. domestic workers. Int J Ment Health. 2011;40(4):3-18. https://doi. org/10.2753/IMH0020-7411400401.

24. Farhan N, Leonhart R, Puffe L, Boeker M, Wirsching M. Communication test for foreign physicians in Germany: the patient communication test Gesundheitswesen. 2016;78(4):215-20. https://doi.org/10.1055/s-0035-1564181.

25. Pantenburg B, Kitze K, Luppa M, König H-H, Riedel-Heller SG. Job satisfaction of foreign-national physicians working in patient care: a cross-sectional study in Saxony, Germany. J Occup Med Toxicol. 2016;11(1):41.

26. Povrzanović Frykman M, Mozetič K. The importance of friends: social life challenges for foreign physicians in southern Sweden. Community Work Fam. 2020;23(4):385-400. https://doi.org/10.1080/13668803.2019.1599323.

27. Schenk L, Bau A, Borde T, Butler J, Lampert T, Neuhauser H, et al. A basic set of indicators for mapping migrant status. Recommendations for epidemiological practice. Bundesgesundheitsbl Gesundheitsforsch Gesundheitsschutz. 2006;49(9):853-60. https://doi.org/10.1007/s00103-0060018-4.

28. Maslach C, Jackson SE, Leiter MP. Burnout inventory manual Palo Alto. CA: Consulting; 1996.

29. Schaufeli WB, Leiter MP, Maslach C, Jackson SE. MBI-general survey (MBI-GS). Palo Alto: Mindgarden; 1996.

30. Chen WS, Haniff J, Siau CS, Seet W, Loh SF, Jamil MHA, et al. Translation, cross-cultural adaptation and validation of the Malay version of the Maslach burnout inventory (MBI) in Malaysia. Int J Soc Sci Stud. 2014;2:66.

31. Chirkowska-Smolak T, Kleka P. The Maslach burnout inventory-general survey: validation across different occupational groups in Poland. Pol Psychol Bull. 2011;42(2):86-94. https://doi.org/10.2478/v10059-011-0014-x.

32. Richardsen AM, Martinussen M. Factorial validity and consistency of the MBI-GS across occupational groups in Norway, vol. 12: Educational Publishing Foundation; 2005

33. Kalimo R, Pahkin K, Mutanen P, Topipinen-Tanner S. Staying well or burning out at work: work characteristics and personal resources as long-term predictors. Work Stress. 2003;17(2):109-22. https://doi.org/10.1080/026783 7031000149919.

34. Syrek C, Bauer-Emmel C, Antoni C, Klusemann J. Entwicklung und Validierung der Trierer Kurzskala zur Messung von Work-Life Balance (TKSWLB). Diagnostica. 2011;57(3):134-45.

35. Peisah C, Latif E, Wilhelm K, Williams B. Secrets to psychological success: why older doctors might have lower psychological distress and burnout than younger doctors. Aging Ment Health. 2009;13(2):300-7. https://doi. org/10.1080/13607860802459831.

36. Claassen K, Broding HC. Mental Strain of Immigrants in the Working Context. Int J Environ Res Public Health. 2019;16:1.

37. Carta MG, Bernal M, Hardoy MC, Haro-Abad JM, The "report on the menta health in Europe" working group. Migration and mental health in Europe (the state of the mental health in Europe working group: appendix 1). Clin Pract Epidemiol Ment Health. 2005;1(1):13 Available from: URL: https://doi. org/10.1186/1745-0179-1-13

38. Nunez-Smith M, Pilgrim N, Wynia M, Desai MM, Jones BA, Bright $C$, et al. Race/ethnicity and workplace discrimination: results of a national survey of physicians. J Gen Intern Med. 2009;24(11):1198-204 Available from: URL: https://pubmed.ncbi.nlm.nih.gov/19727966.

39. May M, Shaar M, Gumz A, Shaar A, Necknig UH, Braun K-P, et al. Zusammenhang zwischen dem Lesen nicht-medizinischer Bücher mit Burnout und beruflicher Zufriedenheit bei Urologen mit Migrationshintergrund-Ergebnisse einer Fragebogenstudie an deutschen Kliniken. Aktuelle Urol. 2021.

40. Umene-Nakano W, Kato TA, Kikuchi S, Tateno M, Fujisawa D, Hoshuyama T, et al. Nationwide survey of work environment, work-life balance and burnout among psychiatrists in Japan. PLoS One. 2013;8(2):e55189 Available from: URL: https://pubmed.ncbi.nlm.nih.gov/23418435.

\section{Publisher's Note}

Springer Nature remains neutral with regard to jurisdictional claims in published maps and institutional affiliations.
Ready to submit your research? Choose BMC and benefit from:

- fast, convenient online submission

- thorough peer review by experienced researchers in your field

- rapid publication on acceptance

- support for research data, including large and complex data types

- gold Open Access which fosters wider collaboration and increased citations

- maximum visibility for your research: over $100 \mathrm{M}$ website views per year

At $\mathrm{BMC}$, research is always in progress.

Learn more biomedcentral.com/submissions 